\title{
Innovation in Sustainable Construction Materials and the Circular Economy
}

\author{
Christopher Cheeseman \\ Centre for Infrastructure Materials, Department of Civil and Environmental \\ Engineering, Imperial College London, South Kensington, London, SW7 2BU \\ Email: c.cheeseman@imperial.ac.uk
}

\begin{abstract}
Although the construction sector is typically highly conservative and risk averse, the opportunities for innovation in construction materials and related technologies have never been greater. This is being driven by factors such as the need to deliver lowcarbon sustainable infrastructure, the use of materials with improved durability and performance, the opportunities to develop multi-functional and smart materials and the circular economy. However, much of the research and development reported in this area, while valuable and technically competent, is relatively incremental and limited in scope. There are of course, good reasons for this, but there is also a need for more innovative research to address some of the issues in construction and infrastructure materials. Universities are often the best place for this type of research given their opportunities to complete research with higher associated risk. This paper provides examples of innovation in construction materials that has been driven by the need to develop a circular economy. The examples are based primarily on the work of the author and associated collaborators.
\end{abstract}

Keywords: Economy; Sustainable Construction Materials

\section{INTRODUCTION}

Fundamental to almost all materials science is the inherent link between materials composition, processing, microstructure, properties and therefore potential applications. This means that materials are not fixed or singular but complex and highly variable. It means the same material composition can have very different properties and that there is always scope to change and develop new materials. As a result the answer to a question regarding properties is almost always 'it depends'. It depends on the composition of the material, it depends on how the material is processed and it depends on the microstructure of the material formed. As a result steel, for example, is hugely variable in its properties despite still being steel. The properties depend on the exact composition and the exact thermal history. The term 'concrete' also refers to materials that can be highly variable in properties and microstructure depending on composition and processing. The properties depend on the exact composition and processing, and this produces a specific microstructure that 
results in specific properties. Change the composition or the processing and the material formed is changed and therefore there are huge opportunities and scope for innovation in materials.

This is particularly important and relevant when trying to develop a circular economy for many 'end of life' materials. It means that there are normally numerous options for 'waste' materials to be transformed into resources and to form new materials that allow the waste to become circular. A conclusion is that waste materials are often designated as 'waste' primarily because no-one has completed the research to make them into a viable raw material or resource. They are effectively waiting for innovation to happen. This simple idea has been a consistent theme in much of my research. The aim of this paper is to provide some examples of this type of innovation process, highlighting in each case the drivers and the associated materials science this can generate.

\section{PROCESSING - MICROSTRUCTURE - PROPERTY STUDIES}

\section{Macro-defect-free (MDF) cements}

During the early 1980s macro-defect free (MDF) cements received significant attention and publicity. Those of a certain age may remember the MDF cement spring that appeared on the BBC popular science programme Tomorrow World. MDF cements were developed in the early 80 s as potential substitutes for plastics, not because of the plastic in the oceans problem or their persistence in the environment but because of the perceived shortage of the raw material used to manufacture plastics following the oil crisis of the mid-1970s.

MDF cements are basically cement paste containing a polymer addition and low water content. This drastically changes the rheological properties of the material. Processing involved either using a twin roll mill or a vacuum extruder, as shown in Figure 1, and this allowed the inherent flaws in a cement paste to effectively be squeezed out of the microstructure. As a result the strengths achieved were impressive, with bending strengths in excess of $150 \mathrm{MPa}$ for samples prepared using high alumina cements.

MDF cements are an example of how a change in composition and processing can drastically influence the properties of a material. Given the ongoing concern over plastics in the environment it was, maybe, a technology ahead of its time (Donatello et al., 2009).

\section{Glass-ceramic processing of wastes}

Ceramic processing from powders generally involves forming a compacted sample of very fine particles with high surface area. When the compacted green sample is heated the particles sinter together, either through solid state sintering, or more typically liquid phase sintering. In either case the driving force is the reduction in total surface area, with the ceramic materials formed generally being much stronger than cementitious materials formed by hydration reactions. 


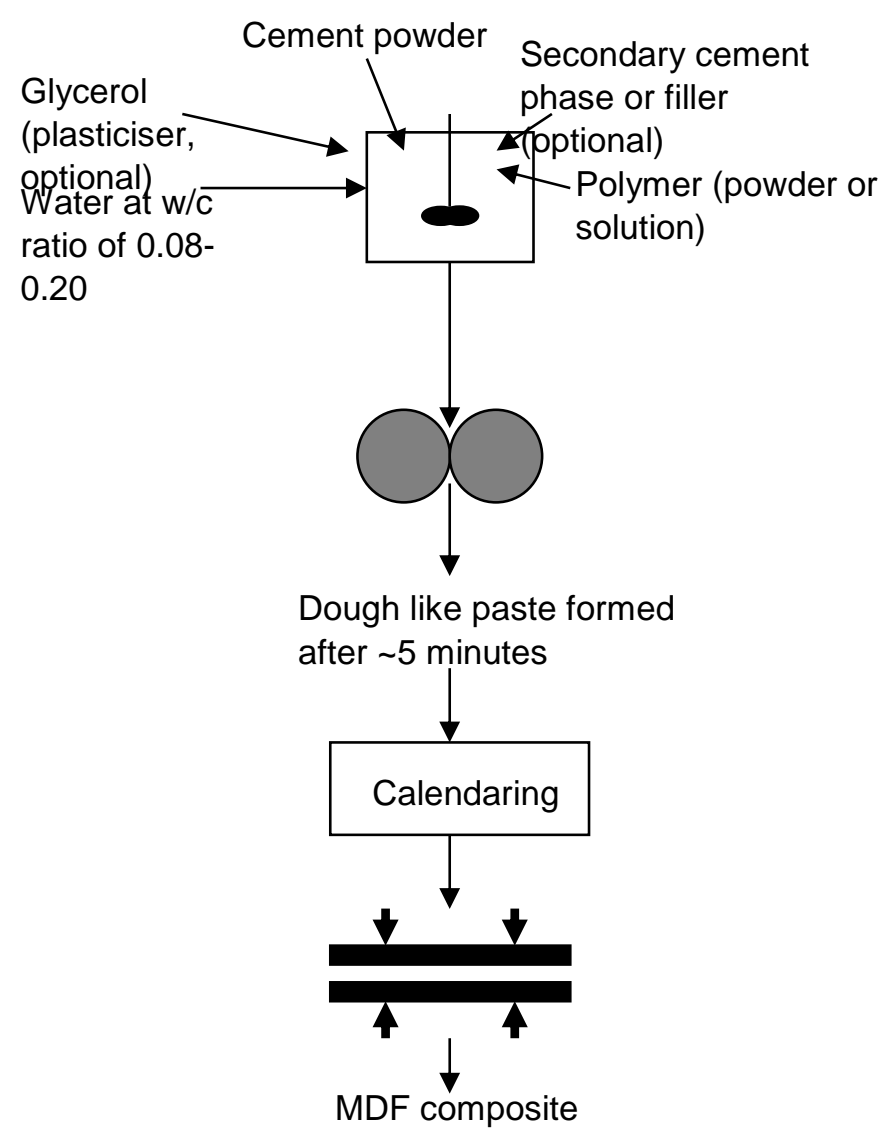

Stage
Premixing in planetary
orbital mixer (optional)

High shear

mixing in twin roll

mill

Involves repeated rolling, folding and stretching of dough

Compaction at up to $6 \mathrm{Mpa}$ (time and temperature can vary)

Curing - time and temperature vary

Fig. 1. Typical manufacturing process used to prepare high strength MDF cement.

This type of ceramic processing is widely used in industry and has been applied to a wide range of predominantly mineral wastes and optimised to produce new glassceramics. Potentially viable glass-ceramics have been produced from lignite coal fly ash (Ilic et al., 2003) as shown in Figure 2, the problematic fine fraction of incinerator bottom ash (Bethanis et al., 2002, Cheeseman et al., 2003a), sewage sludge ash (Cheeseman et al., 2003b), metal finishing wastes (Little et al., 2008), plasma vitrified air pollution control residues (Roether et al., 2010), coal fired power station furnace bottom ash (Glymond et al., 2018) and even red mud, a waste from the aluminium industry. The addition of fine glass powder and other fluxing agents provides further options and scope for materials development via this route.

Although now extensively reported in the literature, sintering wastes to form ceramics, or more accurately glass-ceramics, remains a viable way to process a wide range of wastes into new materials. There are now innovative companies that focus on processing wastes into high quality glass-ceramics that find niche markets primarily exploiting the aesthetic properties of the materials formed. 


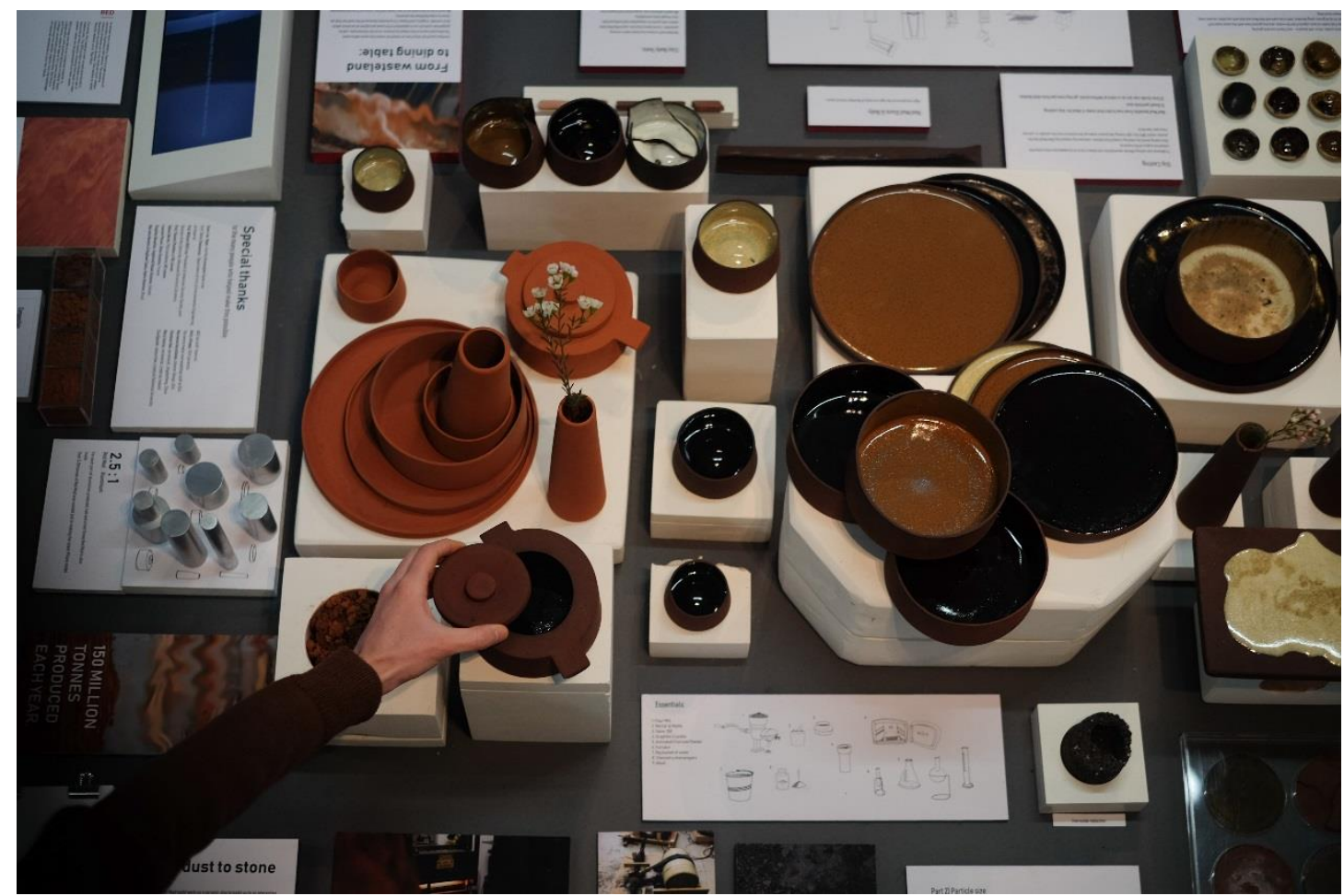

Fig. 2. A selection of ceramic products manufactured by Royal College of Arts students using red mud.

\section{Lightweight materials by controlling porosity}

If sufficient glassy phase is present in the composition of a mineral waste then the addition of a gas forming agent to the mix and careful control of the firing conditions allows the formation of a foamed microstructure with low density. A typical gas forming additive is calcium carbonate that decomposes to $\mathrm{CaO}$ and $\mathrm{CO}_{2}$ at relatively low temperatures and the addition required is typically very low. The major application for foamed ceramics in construction is as lightweight aggregate. These have been produced from incinerator bottom ash (Cheeseman et al., 2005), sewage sludge ash (Cheeseman and Virdi 2005), glass (Velis et al., 2014), paper sludge ash

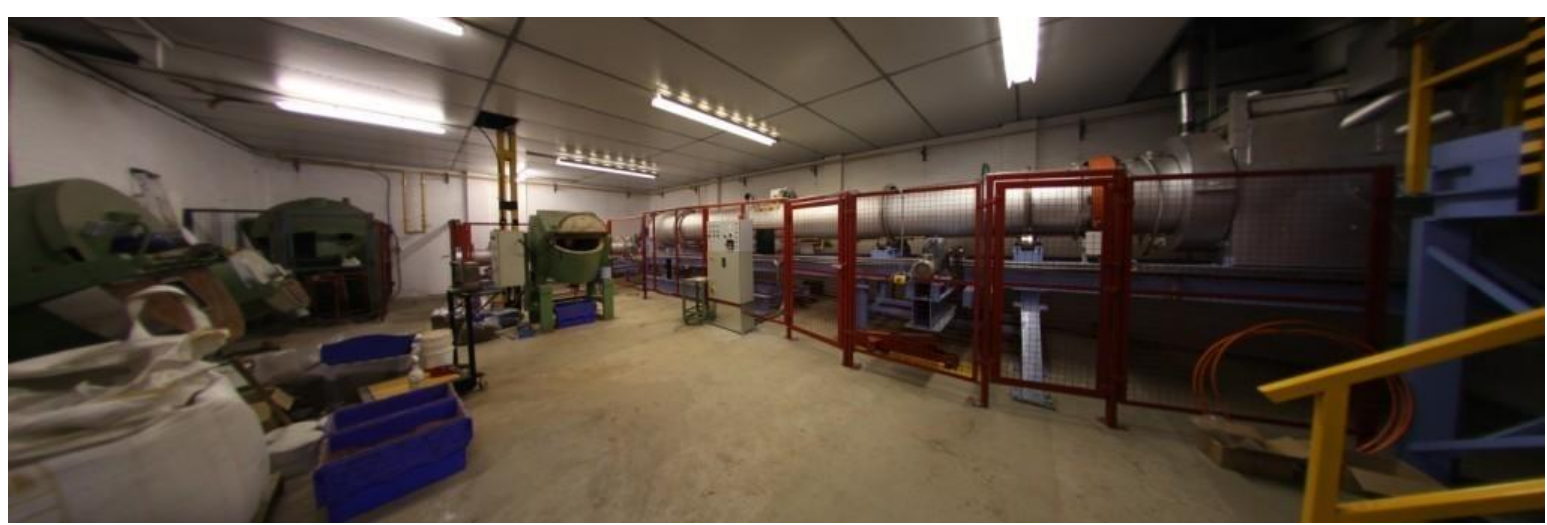

(Spathi et al., 2015) and waste drill cuttings (Ayati et al., 2019). 
Fig. 3. Lightweight aggregate pilot scale production facility showing rotary furnace .

A key factor in the production of a foamed microstructure and a viable lightweight aggregate is the heating rate (Adell et al., 2008). This needs to be rapid so that gas formation occurs as the glassy phase softens so the material has appropriate properties during heat treatment to retain the closed porosity formed (Adell et al., 2007). Lightweight aggregate represents a viable circular product that can be formed from a wide range of wastes provided appropriate quantities are available. It can be particularly solution if the formation temperature is appropriate for the use of biofuels. Probably the most successful 'waste derived' construction product has been Lytag, the lightweight aggregate formed from coal fired power station fly ash using a sinter strand.

\section{Low-carbon cementitious binders}

Portland cement will undoubtedly continue to come under increasing political and public scrutiny because of the carbon emissions associated with cement production. A naïve view would be to think that we could just replace Portland cement with an alternative low-carbon cementitious binder. In reality this is very challenging for many well-documented reasons (Black et al., 2013). The basic raw materials for Portland cement are available throughout much of the world on an appropriate scale for cement production and that does not apply to any viable alternatives. The construction industry is also locked into Portland cement so that alternative cementitious binder need to behave in a similar way during processing. The task is therefore not to develop a new cement but a new cement that behaves in the same way as Portland cement and this is a significant challenge. Portland cement is of course used as a component in concrete, not as a construction material in its own right and concrete really is already a relatively low-carbon material, with the carbon emissions related to the vast quantities of concrete that are used (Flatt et al., 2012).

Alternatives to Portland cement such as geopolymer and alkali activated cement systems have been extensively researched in recent years (Kourti et al., 2011; Kuenzel et al., 2012; Kuenzel et al., 2013). Blended cements using supplementary cementitious materials (SCMs) are also likely to become increasingly important (Tyrer et al., 2010). The development of appropriate SCMs is therefore an active and interesting area for innovation. Coal fly ash and blast furnace slag will remain key materials, but particularly if there are supply issues then the development of commercially viable calcined clays will become increasingly important. Innovation is needed to use, process and control the pozzolanic properties of readily available lower grade clays for use as SCMs in lower carbon cement and concretes and this represents a major opportunity (Zhou et al., 2017).

Recent visits to China have emphasised the importance of $\mathrm{MgO}$ based cements, not necessarily as major competitors for Portland cement, but for use in specific applications and construction products. These include the magnesium oxychloride cements (MOC) and magnesium oxysulphide (MOS) cements (Chen et al., 2019). Our own work on $\mathrm{MgO}$-magnesium hydromagnesite blends produced significant commercial interest and led to the spin-out company Novacem (Vlasopoulos and Cheeseman 2013; Kuenzel et al., 2018). Materials prepared from $\mathrm{MgO}$ and silica that 
react to form magnesium silicate hydrate (M-S-H) gel can be cast to form mortar samples that look and feel like stiff plastics. M-S-H cements have reasonable strengths and very low surface porosity. They do not look or feel like a cementitious material and they could have applications outside construction, particularly given the ongoing public and political momentum behind reducing our reliance on plastics (Zhang et al., 2011; Zhang et al., 2014).

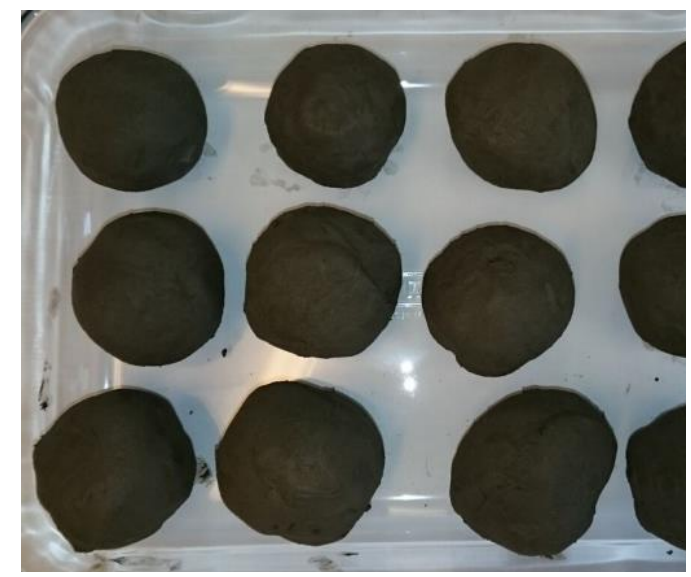

(a)

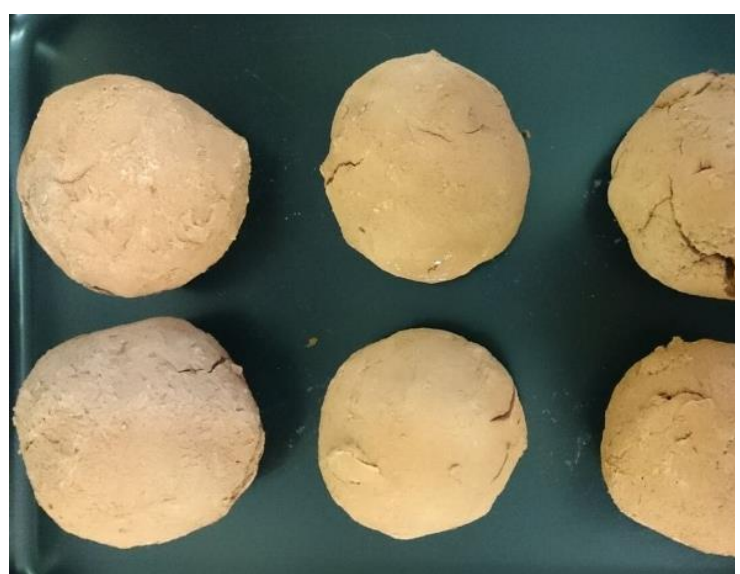

(b)

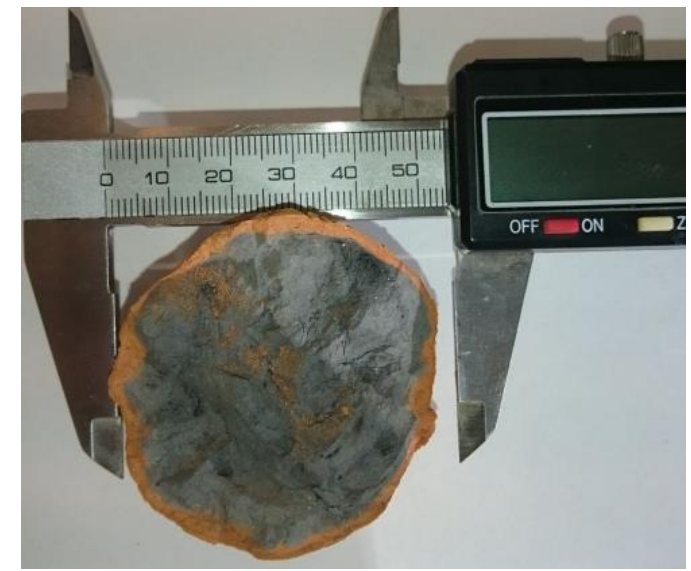

(c)

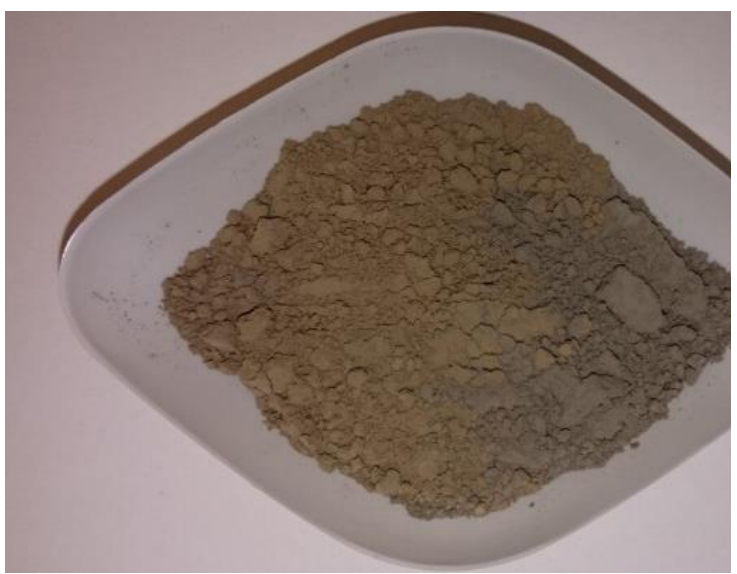

(d)

Fig. 4. Preparation of calcined London clay: a) moist clay shaped into small balls ready to be oven-dried; b) calcined London clay balls showing an orange coloured surface; c) cross-section of the calcined clay showing a brown core; d) calcined London clay in powder form after milling.

\section{Building materials from waste plastics in developing countries}

Recent research has been involved in the development of sustainable construction materials in developing countries, particularly the Cameroon and the Gambia (KumiLarbi et al., 2018). This type of work can have a major impact on local communities by providing employment and useful new construction materials. The rather uncomfortable fact for us in the developed world is that a large percentage of the 
population in many developing countries are living with no viable waste management system, including no waste collection, proper recycling or disposal other than dumping. As a result, plastics are everywhere in the environment and often they are dumped into waterways. From there they are able to be transported to the sea and it is becoming very clear that this is the major source of plastics in the oceans. Developing proper waste management in developing countries would significantly reduce the flow of plastics into the oceans.

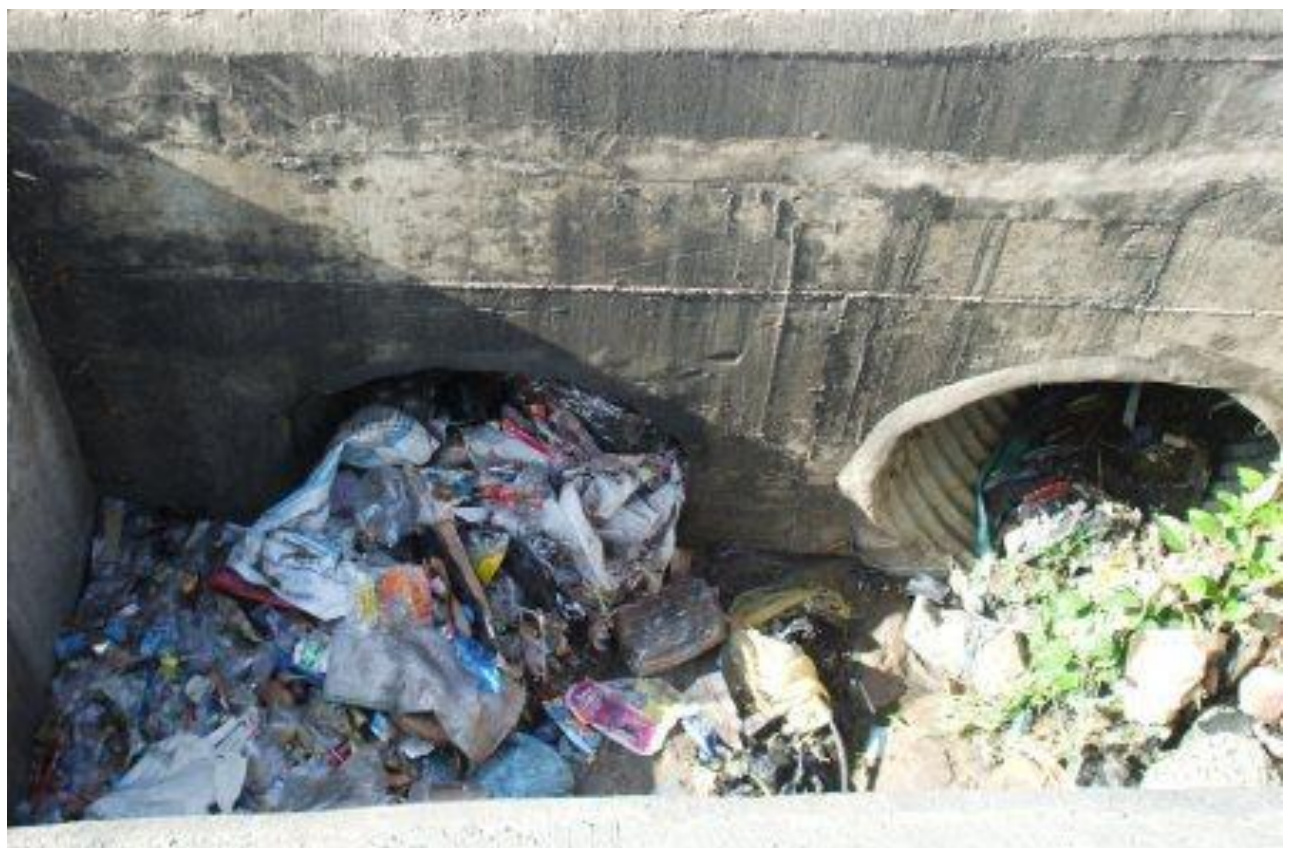

Fig. 5. Waste plastics in Maiduguri, Nigeria blocking drainage infrastructure.

Low-density polyethylene (LDPE) in the form of sheets, bags, packaging and water sachets are a major component of the plastic waste problem in developing countries and as a result, LDPE currently has little or no value. Dumping causes aesthetic, environmental and public health issues. However LDPE is a waste material with huge potential to be processed into new materials. A relatively simple technology has been developed in the Cameroon that does this by producing LDPEbonded sand blocks and pavers. The application of this technology allows community-driven waste management initiatives to develop that have potential to impact on the global plastics waste and plastics in the oceans crisis. It transforms waste LDPE and potentially other readily available plastics into a valuable local resource.

The processing as currently used is simple and involves melting LDPE waste water sachets and mixing in sand to form the new material. The effect of processing and composition variables such as the sand particle size and sand to plastic ratio on density, compressive strength and water adsorption have been investigated. Ongoing research is looking at further optimisation of the process to limit the air pollution and health issues associated with the process. 


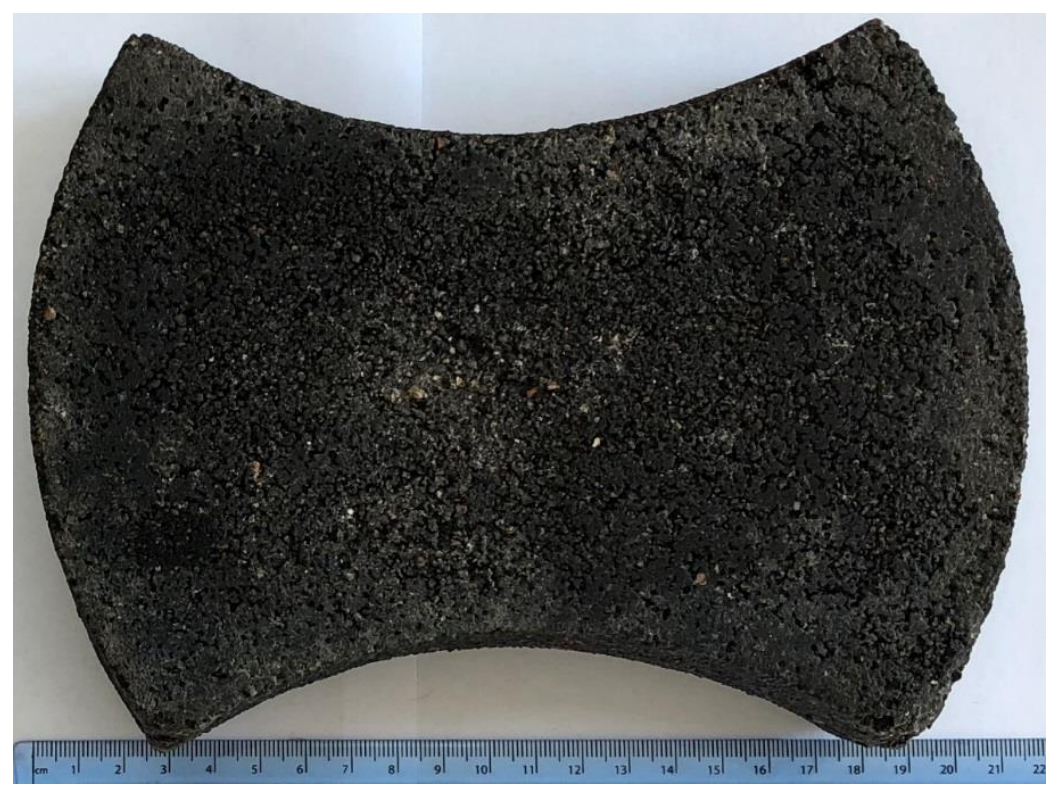

Fig. 6. Sand plastic block made from waste LDPE in the Cameroon.

\section{Developing beneficial reuse applications for waste feathers}

The last example of processing waste into new materials has come from a totally different area. Innovation Design Engineering (IDE) is a leading, creative product development double Master's programme run by the Royal College of Art (RCA) in London and the Dyson School of Design Engineering at Imperial. I was approached by a student from this course to supervise a project on reusing waste feathers.

Feathers are a readily available from the significant quantities of poultry consumed globally. These are mainly from chicken broilers, although turkey and duck consumption is also increasing, with poultry consumption expected to be 14.9 $\mathrm{kg} /$ person/year by 2023. Developing new beneficial reuse applications for waste feathers is therefore an active and increasingly important research area.

Conventional disposal of UK feathers involves autoclaving to produce feather meal, a relatively low-value, low-grade, protein rich animal feed that is exported to Eastern Europe and Russia. Specific types of down feathers are used for filling duvets, garments and upholstery, but these applications can only ever use a very small percentage of the total feathers generated. Waste feathers are normally landfilled or incinerated if no suitable rendering infrastructure is available.

The structure of a feather has the rachis forming the central core that provides stiffness, while the vanes on either side form flat regions with barbs producing a comb like microstructure. Feathers are strong in tension and are primarily composed of keratin, a tough, insoluble filament-forming protein. Feather fibres are biodegradable and can return valuable nutrients to the environment at end of life. In addition feather fibres can often be sourced locally at relatively low-cost. 
a)

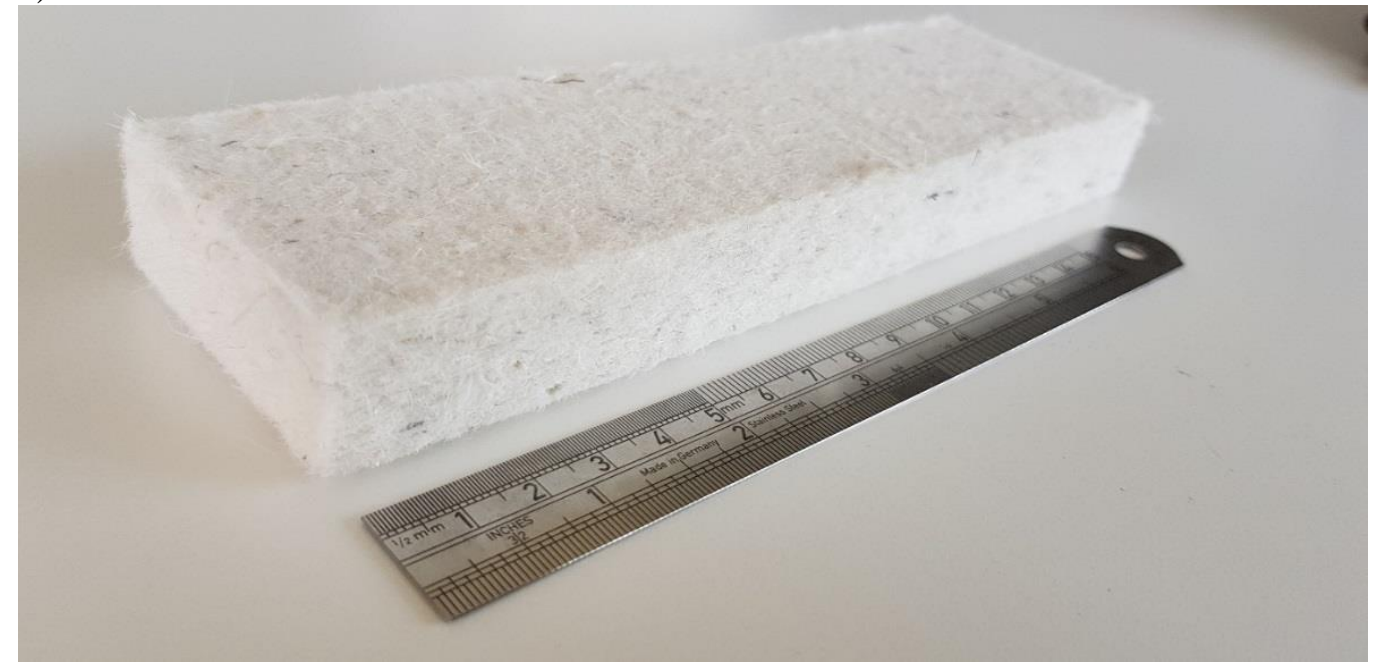

b)

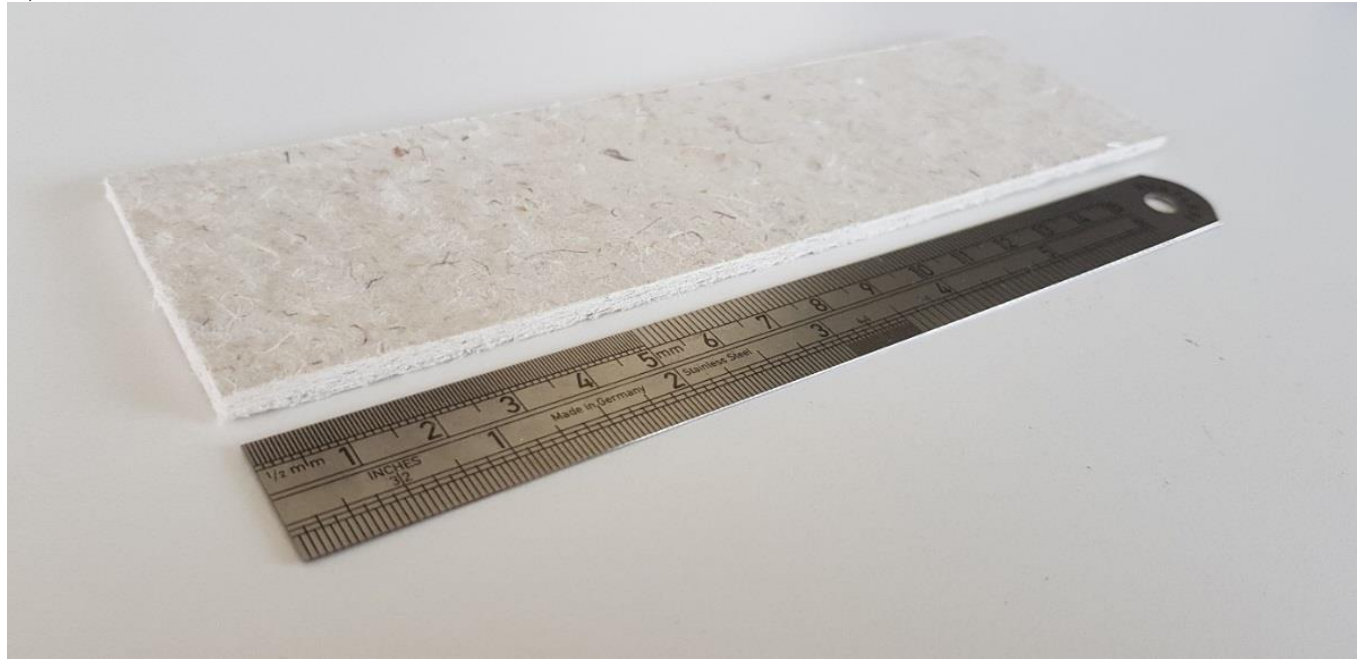

Fig. 7. a) Air-laid non-woven feather fibre samples. b) Feather fibre board manufactured by hot-pressing the air laid non-woven sample in a) at $6 \mathrm{MPa}$ and 154 ${ }^{\circ} \mathrm{C}$ for 60 seconds.

Our research has investigated the properties of materials produced from air laid nonwoven materials containing high levels of feather fibres. This has led to the development of novel thermal insulation products for houses, sustainable thermal insulation packaging (Dieckmann et al, 2019a) low-temperature thermal insulation, sound absorption materials (Dieckmann et al., 2018), oil spill and oil removal products. In addition, hot-pressing air laid feather fibre textiles produces rigid boardtype materials with mechanical properties with potential for use in automotive, construction and civil design applications where there is a strong demand for natural and eco-friendly materials (Dieckmann et al., 2019b). In this work non-woven samples have been hot-pressed at a range of temperatures and pressures and the density, tensile strength, tensile modulus, microstructure and fracture mechanism of different board materials formed are reported. 

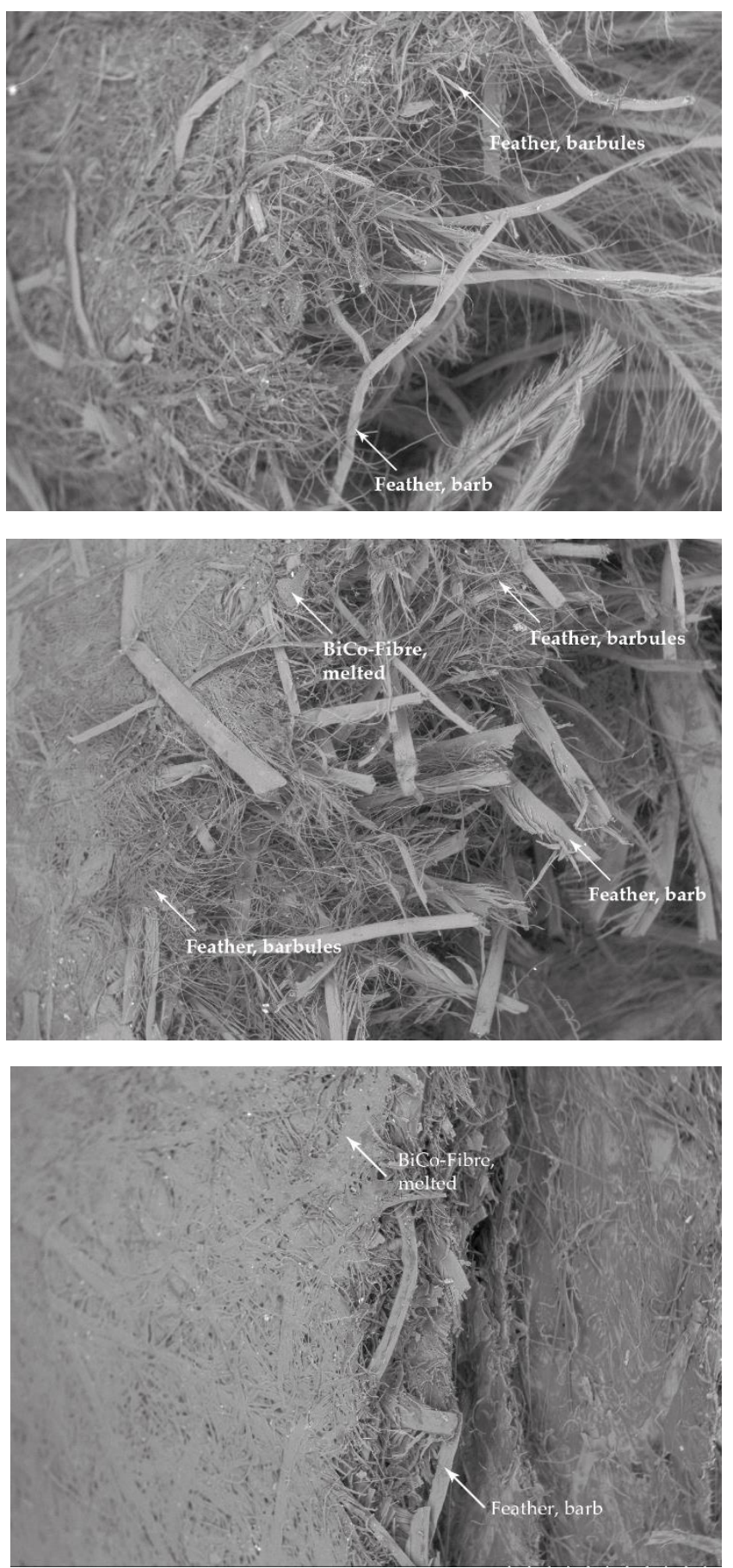

Fig. 8. Fracture surfaces of samples tested in tension: a) hot-pressed at $130^{\circ} \mathrm{C}$ and 6 $M P a$ showing extensive fibre pull out during fracture due to relatively weak feather fibre-binder bonding; b) hot-pressed at $150^{\circ} \mathrm{C}$ and $6 \mathrm{MPa}$ showing improved feather fibre-binder bonding resulting in increased strength and reduced fibre pull-out; $c$ ) hot pressed at $190^{\circ} \mathrm{C}$ and $6 \mathrm{MPa}$. The feather fibres are thermally degraded at this temperature and this results in extensive fibre fracture. 


\section{CONCLUSIONS}

I would like to conclude by thanking the organisers of the Fifth International Conference on Sustainable Construction Materials and Technologies for making me a Conference Honouree. I am not quite sure what I have done to deserve this. To be honest I just think we are all very fortunate to work in such an interesting area. This paper has reviewed aspects of materials research that have formed a key part of my research. This has included work on cements, glass-ceramics, foamed materials, waste plastics and biomaterials. Much of the work has been driven by the need to develop a more circular economy. The consistent theme throughout is that varying the material processing and composition offers scope to develop new materials and that this is an area with huge opportunities for further innovation.

\section{ACKNOWLEDGEMENTS}

I would like to acknowledge the huge number of people who I have worked with over the years. I would particularly like to thank all the MSc students and PhD students I have supervised, plus my many collaborators at Imperial, elsewhere in the UK and internationally. A number of people deserve specific mentions. These are Professor Roger Perry who was responsible for originally bringing me to Imperial, Dr Bill Townend, Professor Chris Coggins, Visiting Professor at Imperial Ellis Gartner and Philip Owens. All had great enthusiasm for work in this field and all are unfortunately no longer with us.

\section{REFERENCES}

Adell V., Cheeseman C.R., Ferraris M., Salvo M., Smeacetto F. and Boccaccini A.R., Characterising the sintering behaviour of pulverised fuel ash using heating stage microscopy, Materials Characterization, 58, (2007), 980-988.

Adell V., Cheeseman C.R., Doel A., Beattie A. and Boccaccini A.R., Comparison of rapid and slow sintered pulverised fuel ash, Fuel, 87, (2008) 187-195.

Ayati B., Molineux C., Newport D. Cheeseman C., Manufacture and performance of lightweight aggregate from waste drill cuttings, J. Clean. Prod., 208 (2019) 252260.

Bethanis S., Cheeseman C.R., Sollars C.J., Properties and microstructure of sintered incinerator bottom ash, Ceramics International, 28, (2002) 881-886.

Black L, Cheeseman C, Tyrer M, Non-conventional cementitious binders, Advances in Applied Ceramics 112 (2013) 177-178.

Cheeseman C.R., Monteiro da Rocha S., Bethanis S., Sollars C., Boccaccini A.R., Ceramic processing of incinerator bottom ash, Waste Management, 23 (2003a) 907-916.

Cheeseman C.R., Sollars C.J., McEntee, Properties, microstructure and leaching of sintered sewage sludge ash, Resources, Conservation and Recycling, 40 (2003b) $13-25$. 
Cheeseman C.R., Makinde A., Bethanis S., Properties of lightweight aggregate produced by rapid sintering of incinerator bottom ash, Resources, Conservation and Recycling, 43, (2005) 147-162.

Cheeseman C.R., Virdi G.S., Properties and microstructure of lightweight aggregate produced from sintered sewage sludge ash, Resources, Conservation and Recycling, 45, (2005) 18-30.

Chen X, Zhang T, Bi W, Cheeseman C.R., Effect of tartaric acid and phosphoric acid on the water resistance of magnesium oxychloride (MOC) cement, Construction and Building Materials, 213 (2019) 528-536.

Dieckmann E, Dance S, Sheldrick L, Cheeseman C.R., Novel sound absorption materials produced from air laid non-woven feather fibres, Heliyon, Volume 4, Issue 9 (2018) Article e00818.

Dieckmann E, Nagy B, Yiakoumetti K, Sheldrick L, Cheeseman C.R., Thermal insulation packaging for cold-chain deliveries made from feathers, Food Packaging and Shelf Life, in press, July 2019a.

Dieckmann E, Eleftheriou K, Audic T, Lee K-Y, Sheldrick L, Cheeseman C.R., New sustainable materials from waste feathers: properties of hot-pressed feather/cotton/bi-component fibre boards, Sustainable Materials and Technologies, 17 (2019b) e00107

Donatello S., Tyrer M., Cheeseman C.R., Recent developments in macro defect free (MDF) cements, Construction and Building Materials, 23 (2009) 1761-1767.

Flatt R.J., Roussel N., Cheeseman C.R., Concrete: An eco-material that needs to be improved, Journal of the European Ceramic Society, 32, (2012) 2787-2798.

Glymond D., Roberts A., Russell M., Cheeseman C.R., Production of ceramics from coal furnace bottom ash, Ceramics International, 3 (2018) 3009-3014.

Ilic, M., Cheeseman C.R., Sollars C. and Knight J., Mineralogy and microstructure of sintered lignite coal fly ash, Fuel, 82 (2003) 331-336.

Kourti I Rani Devaraj A, Guerrero Bustos A, Deegan D, Boccaccini A.R, Cheeseman C.R., Geopolymers prepared from DC plasma treated air pollution control (APC) residues glass: Properties and characterisation of the binder phase, Journal of Hazardous Materials, 196, (2011), 86-92.

Kuenzel C., Vandeperre L., Donatello S., Boccaccini A.R., Cheeseman C.R., Ambient temperature drying shrinkage and cracking in metakaolin-based geopolymers, Journal of the American Ceramic Society, 95 (2012) 3270-3277.

Kuenzel C, Neville T.P, Donatello S, Vandeperre L, Boccaccini A.R., Cheeseman C.R., Influence of metakaolin characteristics on the mechanical properties of geopolymers, Applied Clay Science, 83-84 (2013) 308-314.

Kuenzel C, Li L, Vandeperre L, Boccaccini A.R, Cheeseman C.R., Influence of sand on the mechanical properties of metakaolin geopolymers, Construction and Building Materials, 66 (2014) 442-446.

Kuenzel C, Zhang F, Ferrandiz-Mas V, Cheeseman C.R., Gartner E.M., The mechanism of hydration of MgO-hydromagnesite blends, Cement and Concrete Research, 103 (2018) 123-129.

Kumi-Larbi Jnr A., Yunana D., Kamsouloum P, Webster M, Wilson D.C., Cheeseman C.R., Recycling waste plastics in developing countries: Use of low- 
density polyethylene water sachets to form plastic bonded sand blocks, Waste Management, 80 (2018) 112-118.

Little M.R., Adell V., Boccaccini A.R. and Cheeseman C.R., Production of novel ceramic materials from pulverised fuel ash and metal finishing wastes, Resources, Conservation and Recycling, 52, (2008) 1329-1335.

Roether J.A, Daniel D.J., Amutha Rani D., Deegan D., Cheeseman C.R., Boccaccini A.R., Properties of sintered glass-ceramics prepared from DC plasma vitrified air pollution control residues, Journal of Hazardous Materials, 173 (2010) 563-569.

Spathi C., Vandeperre L.J., Cheeseman C.R., Production of lightweight fillers from waste glass and paper sludge ash, Waste and Biomass Valorization, 3 (2015) 1-7.

Tyrer M., Cheeseman C.R., Greaves R., Claisse P.A., Ganjian E., Kay M.,

Churchman-Davies J., Potential for carbon dioxide reduction from cement industry through increased use of industrial pozzolans, Advances in Applied Ceramics, 109 (2010) 275-279.

Velis C.A., Franco-Salinas C., O'Sullivan C., Najorka J., Boccaccini A.R., Cheeseman C.R., Up-cycling waste glass to minimal water absorption lightweight aggregate by rapid low temperature sintering: optimization by dual process-mixture response surface methodology, Environmental Science and Technology, 48 (2014) 7527-7535.

Vlasopoulos N, Cheeseman C.R., Binder Composition, US Patent 8,496,751 (2013).

Zhang T, Cheeseman C.R., Vandeperre L.J., Development of low pH cement systems forming magnesium silicate hydrate (M-S-H), Cement and Concrete Research, 41, (2011) 439-442.

Zhang T., Vandeperre L, Cheeseman C.R., Formation of magnesium silicate hydrate (M-S-H) cements using sodium hexametaphosphate, Cement and Concrete Research, 65 (2014) 8-14.

Zhou D, Wang R, Tyrer M, Wong H, Cheeseman C.R., Sustainable infrastructure development through use of calcined excavated waste clay as a supplementary cementitious material, Journal of Cleaner Production, 168 (2017) 1180-1192. 